
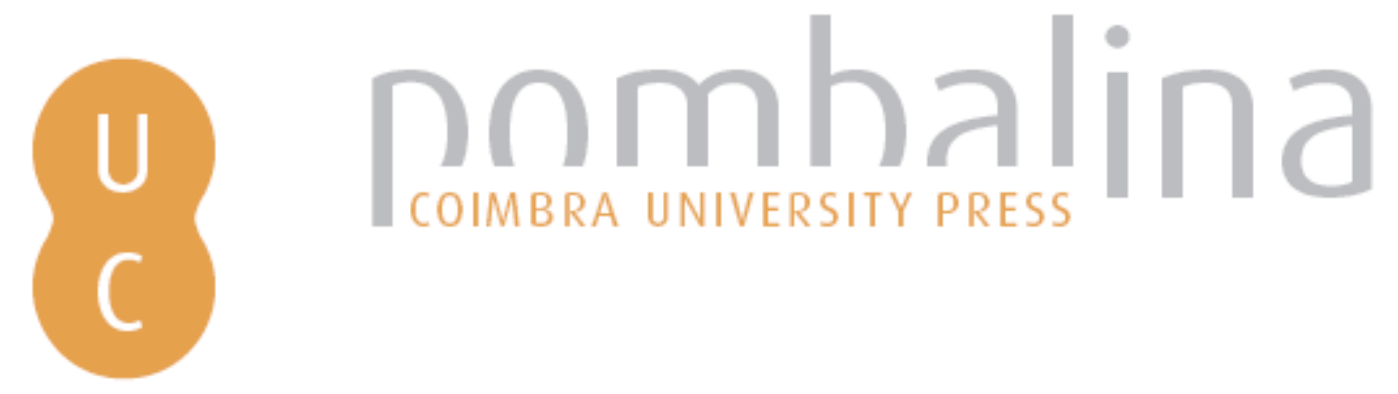

\title{
Acesso a documentos científicos por comutação bibliográfica no Brasil: estudo de caso de biblioteca universitária
}

Autor(es): $\quad$ Rodrigues, Ana Vera Finardi; Miranda, Celina Leite; Crespo, Isabel Merlo

Publicado por: Imprensa da Universidade de Coimbra

URL

persistente: URI:http://hdl.handle.net/10316.2/31947

DOI: DOI:http://dx.doi.org/10.14195/978-989-26-0869-3_34

Accessed : $\quad$ 26-Apr-2023 09:21:35

A navegação consulta e descarregamento dos títulos inseridos nas Bibliotecas Digitais UC Digitalis, UC Pombalina e UC Impactum, pressupõem a aceitação plena e sem reservas dos Termos e Condições de Uso destas Bibliotecas Digitais, disponíveis em https://digitalis.uc.pt/pt-pt/termos.

Conforme exposto nos referidos Termos e Condições de Uso, o descarregamento de títulos de acesso restrito requer uma licença válida de autorização devendo o utilizador aceder ao(s) documento(s) a partir de um endereço de IP da instituição detentora da supramencionada licença.

Ao utilizador é apenas permitido o descarregamento para uso pessoal, pelo que o emprego do(s) título(s) descarregado(s) para outro fim, designadamente comercial, carece de autorização do respetivo autor ou editor da obra.

Na medida em que todas as obras da UC Digitalis se encontram protegidas pelo Código do Direito de Autor e Direitos Conexos e demais legislação aplicável, toda a cópia, parcial ou total, deste documento, nos casos em que é legalmente admitida, deverá conter ou fazer-se acompanhar por este aviso.

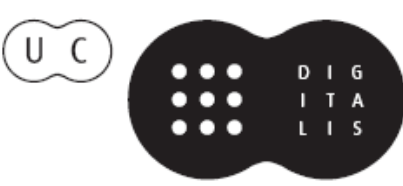


Maria Manuel Borges

Elias Sanz Casado

Coordenação

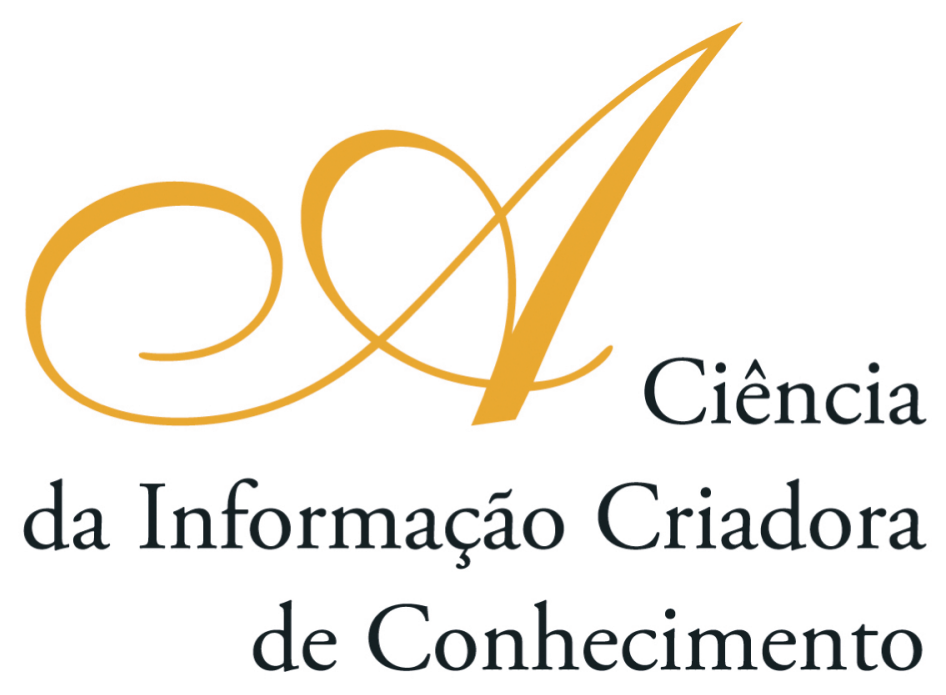

Vol. I I

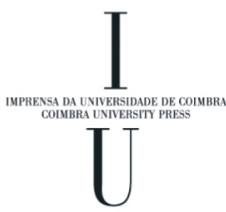

- COImbra 2009 
Acesso a Documentos Científicos por comutação bibliográfica no Brasil: ESTUDO DE CASO DE BIBLIOTECA UNIVERSITÁRIA

\author{
Ana Vera Finardi Rodrigues \\ Pontifícia Universidade Católica de Campinas (Brasil) \\ Celina Leite Miranda \\ Universidade Federal do Rio Grande do Sul (Brasil) \\ Isabel Merlo Crespo \\ Universidade Federal do Rio Grande do Sul (Brasil)
}

\title{
1. Introdução
}

A comutação bibliográfica é um serviço oferecido por bibliotecas, com finalidade de localizar e adquirir cópias de documentos, ou de parte deles, pertencentes ao acervo de outros centros de documentação. O processo se dá através de bibliotecas cooperantes de uma rede, a partir da solicitação prévia de usuários, pelo qual é cobrado apenas o custo de manutenção do sistema. Um dos sistemas de comutação bibliográfica predominante, no Brasil, é o Programa de Comutação Bibliográfica (COMUT) do Instituto Brasileiro de Informaçáo em Ciência e Tecnologia (IBICT), utilizado nesta pesquisa. De acordo com o IBICT, o “[...] Comut foi instituído [...] junto à Coordenaçáo de Aperfeiçoamento de Pessoal de Nível Superior - Capes pela Portaria no 456, de 05 de agosto de 1980" (IBICT, [2006]). No país, buscar cópia de documentos através de grandes bibliotecas, tornou-se fato comum para os pesquisadores. Considerando a dimensão territorial do país, a comutação bibliográfica destaca-se como elemento de suma importância, e tal é a eficiência do sistema citado, que a comunidade usuária se vê plenamente atendida.

\section{Objetivos e metodologia}

Identificadas necessidades de mudanças nas rotinas de comutação da Biblioteca da Faculdade de Veterinária da Universidade Federal do Rio Grande do Sul, Brasil, objetivou-se otimizá-las. Desenvolveu-se, então, um estudo de caso que teve como base a experiência da referida Biblioteca na aplicação de metodologias de comutação bibliográfica. Foram coletados dados, em 2005, através de planilha de atendimento, visando análise do processo de comutaçáo - da solicitaçáo ao atendimento (Rodrigues, Miranda \& Crespo, 2008). 


\section{Resultados da pesquisa}

Através de observação dos formulários preenchidos no ano de 2008, em continuidade à mesma pesquisa realizada em 2005, foram detectados problemas novos e remanescentes. $\mathrm{Na}$ pesquisa de 2005, identificou-se a necessidade de mudanças nas rotinas, as quais foram aplicadas entre 2006 e 2008. Comparando dados de 2005 e 2008 (Fig. 1), percebeu-se aumento na demanda e redução no prazo de recebimento do material solicitado. Houve crescimento no número de pedidos cancelados - em 2005, por preenchimento de formulários e fluxo inadequados; em 2008, apenas 3 cancelamentos ocorreram por esse motivo, além de: documento indisponível, desistência do usuário e desatualização do sistema.

Tabela 1 - Dados comparativos da pesquisa: 2005 e 2008.

\begin{tabular}{|l|l|l|l|l|}
\hline ANO & ATENDIDOS & REPASSADOS E ATENDIDOS & CANCELADOS & TOTAL \\
\hline \multirow{2}{*}{2005} & $109(80,15 \%)$ & $10(7,35 \%)$ & 17 & 136 \\
\cline { 2 - 4 } & $119(87,5 \%)$ & $22,5 \%)$ & $(100 \%)$ \\
\hline \multirow{2}{*}{2008} & $178(83,96 \%)$ & $12(5,66 \%)$ & $(10,38 \%)$ & $\begin{array}{l}212 \\
(100 \%)\end{array}$ \\
\cline { 2 - 6 } & $190(89,62 \%)$ &
\end{tabular}

Embora sem diferença significativa nos totais percentuais, salienta-se que as causas dos cancelamentos se devem a problemas externos à equipe. Dos 178 pedidos atendidos em 2008, o tempo de espera pelo documento variou de horas a 25 dias (Fig. 2); mais de 50\% dos solicitantes (107 formulários) aguardou no máximo 2 dias - uma drástica redução de prazo sobre 2005 .

Tabela 2 - Freqüência de pedidos atendidos em 2008.

\begin{tabular}{|l|l|l|l|l|l|l|l|l|l|l|l|l|}
\hline FREQÜĈNCIA DE PEDIDOS ATENDIDOS EM 2008 \\
\hline Em dias & Mesmo dia & 1 dia & 2 dias & 3 dias & 4 dias & 5 dias & 6 dias & 7 dias & 9 dias & 12 dias & 25 dias \\
\hline Pedidos & 10 & 65 & 32 & 21 & 18 & 13 & 12 & 4 & 1 & 1 & 1 \\
\hline Total & 178 pedidos atendidos \\
\hline
\end{tabular}

Analisadas as rotinas e entraves do serviço, observou-se que: sua utilização solicitando ou atendendo pedidos de cópias -, quando elevada, pode ser valorizada pelos governos, pois o investimento no setor está diretamente ligado ao volume de transaçóes; os dois grandes fornecedores brasileiros possuem sistema diferentes, mas, ao usuário, o resultado é similar.

\section{Consideraçóes finais}

As novas rotinas mostraram-se positivas, apontando: êxito na obtenção do documento solicitado; prazo compatível com a expectativa; redução de cancelamentos por falha do centro solicitante. A atualização das informaçôes relativas ao atendimento (baixas não registradas, biblioteca fechada - inventário, reforma, férias) evita cancelamentos, 
valorizando o tempo do usuário e do bibliotecário. Além disso, estas novas rotinas permitem a promoçáo de educaçáo continuada e treinamento do usuário, através de manuais e tutoriais.

\section{Referências bibliográficazs}

IBICT (2006). Manual do sistema. [Brasília, DF]. Retrieved 21 Apr. 2009, from http://comut. ibict.br/comut/help/ajuda.jsp?link=ajuda.html\%23_Toc59336939.

Rodrigues, A.V.F., Miranda, C.L. \& Crespo, I.M. (2008, enero/marzo). Verificaçăo bibliográfica. Biblios, 30, 1-12. Retrieved 1 May 2009, from http://www.revistabiblios.com/ojs/index. $\mathrm{php} / \mathrm{biblios} /$ article/viewfile/19/29. 